\title{
Electronic identification systems reduce the number of wrong components transfused
}

Authors: Michael F Murphy ${ }^{1,2}$, Jayne Addison $\mathrm{J}^{1,3}$, Debbi Poles ${ }^{3}$, Paula Dhiman ${ }^{2,4}$, Paula Bolton-Maggs ${ }^{3,5}$

\section{Departments and Institutions:}

1) NHS Blood \& Transplant (NHSBT)

2) Oxford NIHR Biomedical Research Centre, Oxford University Hospitals, University of Oxford

3) Serious Hazards of Transfusion (SHOT) scheme, Manchester

4) Centre for Statistics in Medicine, Nuffield Department of Orthopaedics, Rheumatology and Musculoskeletal Sciences, Botnar Research Centre, University of Oxford

5) University of Manchester

Address Correspondence to: Professor M F Murphy, NHS Blood \& Transplant, John Radcliffe Hospital, Oxford OX3 9BQ. mike.murphy@nhsbt.nhs.uk

+44-1865-447902 (phone); +44-1865-447975 (fax)

The authors declare no conflicts of interest.

Word count: 3843 (excluding abstract, references, tables and figures); abstract 249 words.

Key words: Wrong blood component transfused, manual transfusion process, electronic identification system

Running head: Electronic identification systems reduce the number of wrong components transfused 


\section{Abstract \\ Background}

Errors in hospital transfusion may cause wrong (blood) components to be transfused (WCT). This study assessed the value of electronic identification systems (EIS) in reducing WCTs.

\section{Methods}

UK hospitals reporting to Serious Hazards of Transfusion (SHOT) were invited to complete an electronic survey about transfusion including the use of EIS. Further information was requested for WCTs and near miss WCTs.

\section{Results}

A response rate of 93/222 (42\%) hospitals accounted for $38 \%$ of UK blood component issues in 2015 and 2016. 33/93 (35\%) hospitals employ manual procedures and 16/93 (17\%) use EIS throughout the transfusion process; most of the remainder use EIS for blood collection only. 57 WCTs were identified in approximately 2 million blood components. The primary error was at blood draw and sample labeling (3), blood collection (15) and administration (2); the remainder were mostly blood bank errors. No WCTs occurred with blood draw and sample labeling or administration using EIS. 3 WCTs occurred with EIS for blood collection due to incorrect processes for emergency transfusions of group O blood without any adverse effects. 17 WCTs occurred with manual processes; one was an ABO incompatible red cell transfusion resulting in renal impairment. Near miss WCTs were also more frequent with manual procedures than EIS at blood draw and sample labeling and blood collection.

\section{Conclusions}

This is the first multicenter study to demonstrate a lower incidence of WCTs and near miss WCTs with EIS compared to manual processes, and highlights some limitations of both manual and EIS procedures. 


\section{Introduction}

Hemovigilance systems continue to report instances of wrong (blood) component transfusion (WCT), some of which are ABO incompatible transfusions with serious consequences for patients. ${ }^{1,2}$ Since 1996 the Serious Hazards of Transfusion (SHOT) scheme has been collecting and analysing anonymised information on adverse events and reactions in blood transfusion from all healthcare organisations that are involved in the transfusion of blood and blood components in the United Kingdom. ${ }^{1}$ Where risks and problems are identified, SHOT produces recommendations in its annual reports to improve patient safety. There were 4 ABO incompatible red cell transfusions reported to SHOT during 2016 and 2017. ${ }^{1,3}$ However, this was just the tip of the iceberg as 606 WCT near miss events were reported which could have led to $\mathrm{ABO}$ incompatible transfusions but were detected and prevented before the transfusion was given. 566/606 (93\%) were 'wrong blood in tube' events (WBITs), and if they had not been detected in the blood bank, they may have led to WCTs with the potential to cause patient harm. The Food and Drug Administration (FDA) in the United States reported 2 definite and 2 possible transfusion-related fatalities due to ABOincompatible transfusion in 2016 and 1 probable/likely death in $2017 .^{2}$

Errors at any step of the transfusion process can cause WCTs. These steps include patient registration, blood draw and sample labeling, compatibility testing and issue of blood components from the blood bank, the collection and delivery of blood, and the administration of blood. ${ }^{4,5}$ Many efforts have been made to document and/or reduce the errors that cause WCTs including initiatives for the education and training of the many staff involved at each step of the transfusion process. ${ }^{7}$ There have been several studies exploring the value of electronic identification systems (EIS) to reduce WCTs. ${ }^{8-11}$ Some have focussed on a specific step of the process and others have explored 'end-to-end' electronic processes.

There are significant challenges in developing and implementing EIS ${ }^{12}$, and there are few data about how widespread the implementation of these systems has been. The studies demonstrating their value in reducing transfusion errors have predominantly been single center studies $^{7-9}$, the exception being the recent study conducted by the BEST Collaborative showing electronic patient identification for sample labeling reduces WBITs. ${ }^{11}$ The study reported here used data collected by the SHOT hemovigilance scheme to assess the implementation of EIS and compare the frequency of WCTs and near miss WCTs in hospitals using standard manual procedures for transfusion and those using EIS at one or more steps of the transfusion process. 


\section{Methods}

All UK organizations reporting to SHOT were invited to complete an electronic survey with questions about their transfusion processes including the use of EIS. Further information was requested for each case of WCT or WCT near miss reported to SHOT in 2015 and 2016 and if it occurred with an electronic or manual process.

SHOT defines WCT as an incident when a patient was transfused with a blood component of an incorrect blood group, or which was intended for another patient and was incompatible with the recipient, or which was intended for another recipient but happened to be compatible with the recipient, or which was other than that prescribed e.g. platelets instead of red cells. ${ }^{1}$ A WCT near miss event refers to any error which if undetected, could result in the determination of a wrong blood group or transfusion of an incorrect component, but was recognized before the transfusion took place.

The invitation to hospitals to participate was distributed via email from SHOT. Data collection was divided into two parts and reporters were given a period of two weeks to complete part one and two weeks to complete part two. Non-responders were followed up on one further occasion and given further time to complete and return the requested data.

The first stage of the study comprised a questionnaire via an on-line tool (SurveyMonkey) (Appendix 1). The survey asked questions in relation to the use of a manual procedure or EIS at the 3 key steps of transfusion in hospitals, namely:-

1) blood draw and sample labeling;

2) at the point of collection and delivery of blood;

3) at the bedside for the administration of blood.

The questionnaire also asked for information about the proportion of units of blood components using a manual procedure or EIS at each of these steps of the transfusion process in hospitals. SHOT collects data on the issues of blood components from UK blood services to each hospital allowing a calculation of how many blood components utilized a manual procedure or EIS at each step of transfusion in each hospital. In turn, a calculation of how many and what proportion blood components utilized a manual procedure or EIS at each step of transfusion was made for all hospitals reporting to SHOT. Where a hospital provided a range of use of EIS e.g. 31-50\%, the lower figure was taken to estimate the number of 
procedures performed using EIS. The total number of blood components issued in the UK was taken from the SHOT annual reports for 2015 and 2016. ${ }^{3,13}$

In the second stage of the study, those organizations that had reported a WCT or a WCT near miss to SHOT during 2015 or 2016 were asked to complete a spreadsheet providing further information on each case, specifically to provide information about what step of transfusion the WCT or near miss WCT occurred and whether it occurred with a manual procedure or EIS. This enabled estimation of the rate of WCTs or WCT near misses at each step of transfusion, and a comparison of the rate with manual procedures and EIS.

The rate of WCTs and WCT near misses were compared between manual procedures and EIS for each step in the transfusion process where the error occurred. Comparisons were made using a Chi-squared test, or Fisher's exact test if any cell count of the $2 \times 2$ contingency table was less than five. Crude odds ratios (ORs) and their 95\% confidence intervals were calculated for WCTs and WCT near misses. A continuity correction of 0.5 was applied to each cell count of the $2 \times 2$ contingency table if no WCTs or near miss WCTs were reported to calculate the crude odds ratio. ${ }^{14}$

\section{Results}

Survey of practice

93/222 (42\%) of the hospitals reporting to SHOT responded to the survey allowing analysis of $1,946,386 / 5,060,423$ (38\%) of all units of blood components issued to UK hospitals in 2015 and 2016 and a review of their transfusion processes.

$33 / 93(35 \%)$ hospitals indicated they use a manual procedure for all three key steps in the transfusion process (Table 1). 16/93 (17\%) use EIS for all three key steps, 8/93 (9\%) for two steps, 3/93 (3\%) for sample and blood collection, and 5/93 (5.4\%) blood collection and administration. The remaining 36/93 (39\%) use EIS for blood collection only. No hospitals used combinations of EIS that are not represented in Table 1, for example no hospitals used EIS for blood sampling and administration only.

The first EIS introduced for transfusion in the hospitals responding to the survey was for blood collection from the designated storage site in 1999, followed by the first bedside administration system in 2005 (Figure 1). An electronic system for blood draw and sample labeling was first implemented in the hospitals responding to the survey in 2006. The implementation of EIS for administration of blood peaked in 2008, but appears to have slowed since 2014 . 
In hospitals using an EIS, it is not necessarily used for all transfusions. Figure 2 illustrates this point by showing the range in the proportion of transfusions where an EIS was used for each of the three steps of the transfusion process in 2016. For example, only 7 hospitals were using an EIS for $>90 \%$ of blood draw and sample labeling and only 15 hospitals were using an EIS for bedside administration. There was little change in the use of EIS between 2015 and 2016 (data not shown).

Transfusions and WCTs associated with either manual procedures or EIS

The number of blood components issued to hospitals using manual procedures for all 3 steps in the transfusion process was 661,380/1,946,386 (34\%) during the study period (Table 1). 552,994/1,946,386 (28\%) of blood components were issued to hospitals that had an EIS although it was not being used at the time that the transfusion procedure was carried out. The remaining procedures occurred in hospitals using an EIS for one or more of the 3 key steps of the transfusion process, that is $18 \%$ where there was an EIS for all 3 steps of transfusion, 3\% where there was an EIS for blood collection and for administration, $1 \%$ where there was an EIS for blood sampling and for blood collection, and 15\% where there was only an EIS for blood collection.

In 2015 and 2016, 145 WCTs were reported by 87 hospitals to SHOT, and 57/145 (39\%) of them occurred in the hospitals responding to the survey. 20/57 (35\%) occurred at blood draw and sample labeling (3), blood collection (15) or bedside administration (2) (Supplementary Table 1). 17/20 (85\%) occurred with manual procedures in one of these 3 key steps of transfusion; 3 occurred at blood draw and sample labeling, 12 at blood collection and 2 at blood administration. Only $3 / 20$ (15\%) of the WCTs occurring at blood sampling, blood collection or bedside administration occurred with an EIS and all 3 were all at blood collection; they were all related to the collection of emergency group $\mathrm{O}$ blood. They are described in detail below, and none resulted in harm to the patient:-

\section{Case 1}

A pediatric emergency O D-negative red cell unit was collected and subsequently transfused instead of an adult emergency O D- negative unit. In this hospital, the removal of emergency blood is exempt from formal checking by the EIS. The manual administration step also failed to identify the error and the patient received the wrong blood unit.

\section{Case 2}

An adult emergency O D-negative red cell unit was collected and subsequently transfused instead of a pediatric emergency $\mathrm{O} D$-negative unit. The nurse collecting the blood could not $\log$ into the obstetric refrigerator, so a midwife did this for her. Neither the pediatric or adult 
units would scan and in the confusion the adult unit was taken to the bedside instead of the pediatric unit.

\section{Case 3}

A midwife left the door open of the delivery suite blood refrigerator. Another member of staff, untrained in the collection procedure, collected an inappropriate unit of emergency stock (adult O D-positive unit rather than O D-negative). The patient's blood group was subsequently found to be D-positive.

Indeed, none of the 57 WCT cases reported here was associated with the death of the patient. Only one was associated with major morbidity associated with miscollection of the sample using a manual procedure as described below ${ }^{3}:-$

\section{Case 4}

A 61-year-old male was admitted for coronary artery bypass graft. He received four units of group A D-positive red cells. He had an uneventful stay in hospital and was discharged home. Fourteen days later he was admitted to critical care via the emergency department with renal impairment and a falling hemoglobin. On this second admission he was grouped as $\mathrm{O}$ D-positive. The sample used for the compatibility testing 14 days previously had been taken from the wrong patient and labelled incorrectly. A second sample was not obtained to confirm the ABO group although it was the hospital policy. The investigation revealed that the trolley containing all patient request forms and labels was taken to the bedside. While the sample was being taken a colleague placed another set of labels on top of the current sets. The member of staff then labelled the sample using the incorrect labels and did not fully identify the patient.

A comparison of the rate of WCTs with manual procedures and EIS is shown in Table 2. Decreased odds of WCTs were found using EIS compared to manual procedures for draw and sample labeling, and blood administration, where there were no WCTs with EIS. A 59\% lower odds of WCTs was found using EIS when collecting blood compared to using manual process (OR: 0.41 ; $95 \%$ CI: 0.12 to 1.47 ; $=0.191$ ).

In the majority of the remaining WCTs (31/37 cases) (Supplementary Table 1$)$, the primary error for the WCT occurred in the blood bank, either at the point of sample receipt (5), testing (17), component selection (8), component labelling (1).

Near miss WCTs associated with EIS

The study captured near miss events that could have led to a WCT if not detected. There were 1713 cases reported to SHOT from 206 hospitals during 2015 and 2016 and 571 (33\%) were captured in this study. 484/571 (85\%) occurred with manual procedures for draw and sample labeling, collection of blood from a refrigerator or bedside administration, and $37 / 571$ (6\%) with EIS for these steps (Supplementary Table 2). $452 / 497$ (91\%) of the manual 
process errors were with draw and sample labeling. The 37 errors with EIS occurred at blood draw and sample labeling (17) or bedside administration (20).

$427 / 452$ (94\%) primary errors made at the point of sampling with manual systems were detected in the blood bank (Supplementary Table 3). All 17 primary errors that were made at the point of sampling with EIS were also detected in the blood bank. The collection errors with manual procedures were detected at the point of administration of blood or during collection; there were no near miss WCTs with collection using EIS. There were 22 errors that occurred during the administration of blood but they were all detected by either using manual checking (2) or EIS (20).

A comparison of the rate of near miss WCTs with manual and EIS is shown in Table 3. An $84 \%$ and $97 \%$ reduced odds of near miss WCTs were found when using EIS for draw and sample labeling and collection of blood (OR: 0.16 ; 95\% CI: 0.10 to 0.35 ; $\mathrm{p}<0.001$ and OR: 0.03 ; $95 \%$ CI: 0.00 to 0.44 ; $<<0.001$ ), respectively. The reverse was the case for near miss WCTs at blood administration; there were much higher odds of near miss WCTs with EIS than with a manual process (OR: 37.39 ; $95 \%$ CI 8.74 to $159.99 ; \mathrm{p}<0.001)$.

\section{Discussion}

WCT causing morbidity and in some cases death remains an important preventable complication of transfusion. ${ }^{1,2}$ Errors leading to WCT occur at every step of the transfusion process in hospitals. ${ }^{4,5,6}$ SHOT previously found that $21 \%$ of errors resulting in "wrong blood events' are made at the time of prescription, sampling and request, 37\% in the blood bank, and $40 \%$ when blood is collected from the blood bank or administered. ${ }^{15}$

This observational study of WCTs used data from the long-established SHOT hemovigilance scheme to compare the occurrence of WCTs between manual procedures and EIS for blood sampling, blood collection and its administration. In this study using data from 2015 and 2016, there were no WCTs with EIS at the bedside, either at blood draw and sample labeling ( 0 in 376,323 units) or administration of blood ( 0 in 410,677 units), , compared with a rate of 1 in 523,354 units transfused for a manual procedure for draw and sample labeling and 1 in 267,854 units transfused for a manual procedure for blood administration. The rate of WCT for blood collection from a blood refrigerator was less with EIS than a manual procedure; it was 1 in 101,195 for manual and 1 in 244,004 for EIS.

The WCTs associated with blood collection using EIS all occurred in emergency situations, where the wrong group O blood was collected, either a mix-up of pediatric and adult units or selection of a group O D-positive unit rather than D-negative, but there were no 
adverse effects for the patients. One of the WCTs occurring with a manual procedure due to WBIT resulted in an $\mathrm{ABO}$ incompatible red cell transfusion of 4 units causing renal impairment.

The 3 WCTs that occurred using an EIS at the point of collection of blood components from the blood refrigerator illustrate some useful points when considering implementation of EIS for blood collection and some potential pitfalls if hospitals currently have EIS for collection. Case 1 demonstrates the importance of ensuring that the EIS procedure is simple to follow and has the capability of being used for collecting emergency units. The EIS in this case was unable to differentiate between different types of components that are removed in emergency situations because the emergency process allowed bypassing the essential scanning step which would ordinarily detect an error. Cases 2 and 3 both occurred in maternity units and staff members allowed staff, who did not have authorization to collect blood, to remove the blood units. All 3 cases occurred in urgent circumstances, time was pressured, and standard procedures were not followed.

Near miss WCTs cases that were using EIS at the point of sampling and administration also illustrate useful points for consideration when using EIS at these steps or when implementation is being considered. The rate of near miss WCTs was 1 in 3,474 for manual blood draw and sample labeling and 1 in 22,137 for EIS. All these cases were identified in the blood bank and did not proceed to actual WCTs. These data confirm the results of a recent study from the BEST Collaborative which found an approximately fivefold reduction in WBITs with electronic compared to manual procedures. ${ }^{11}$ Although near miss WCTs using EIS for blood sampling were less frequent than with a manual process, the 17 WBIT sampling near miss cases using EIS demonstrate how easy it can be to generate printed labels from identification bands that are not attached to patients or to use wrong labels which have been generated away from the bedside.

UK guidelines recommend that unless secure electronic patient identification systems are in place, a second confirmatory blood sample should be requested for confirmation of the $\mathrm{ABO}$ group of a first-time patient prior to transfusion, where this does not impede the delivery of urgent blood components. ${ }^{16}$ This study did not explore compliance with this recommendation so we do not know how many WBITs were detected by the second sample policy and how many by other means such as the presence of a historical blood group in the patient's blood bank records. 
There were no near miss WCTs for blood collection with EIS (0 in 732,012 units) and 1 in 41,379 units for manual blood collection. The rate of near miss WCTs 1 in 20,533 units for the administration of blood with EIS and 1 in 767,854 units with a manual process. This result may at first sight appear surprising, but it illustrates key points about the way that EIS is used in practice. Review of the 20 administration near miss WCTs using EIS revealed staff approached the wrong patient in 13 cases. These errors occurred immediately prior to the pretransfusion checking process and were detected by the EIS alerting them of an error. This demonstrates the value of EIS in the avoidance of WCTs, but raises concerns about overreliance on electronic scans of the patient's wristband and the blood unit and that staff are bypassing routine patient identification steps such as asking conscious patients to state their name and date of birth and checking the details on the wristband and the blood unit. These key manual steps of patient identification are prompted by the handheld used for bedside checking using the EIS and precede electronic scanning of barcodes on the patient's wristband and the blood unit. The near miss WCTs at the bedside illustrate the strength of EIS in preventing a WCT, as a WCT would not be prevented if similar patient misidentification had occurred using manual procedures, but indicate over-reliance on the scanning steps to identify a WCT. The risk of over-reliance on EIS has been recognized previously ${ }^{5}$, and highlights the importance of thorough training and continued support for the staff undertaking the procedures and follow-up of near miss events and providing re-training as required.

The limitations of this study include that WCT and near miss WCT were rare outcomes even in this large 2-year dataset from a national hemovigilance scheme. This study was not powered to detect meaningful differences between these outcomes for EIS and manual processes, reflected in the wide $95 \%$ confidence intervals. In addition, it was not a comprehensive representation of practice in UK hospitals as the response rate to the survey was $42 \%$ representing 38\% of blood components issued to UK hospitals in 2015 and 2016. However, the responders to the survey were representative of hospitals participating in SHOT. 81/93 responders to the survey provided sufficient additional information to provide this analysis and showed they were representative of all participants in the SHOT program with the exception of the minority of hospitals (25\%) with either very low blood component usage (up to 1000 units/year) who were under-represented (1/18, a $6 \%$ response rate) or very high usage (over 20,000 units/year) who were over-represented (22/32, a $69 \%$ response rate). The majority of hospitals (75\% of SHOT participants) with either low usage (1,001-7,000 units/year), medium usage (7,001-12,000 units/year) or high usage (12,001-20,000 units/year) 
were well represented with respective response rates of 18/57 (32\%), 25/57 (44\%) and 15/39 (39\%) compared to the overall response rate of $42 \%$. The response rate in the 4 countries of the UK was 69/154 (45\%) in England, $1 / 5$ (20\%) in Northern Ireland, 8/15 (53\%) in Scotland and $3 / 6(50 \%)$ in Wales.

Some hospitals were unable to provide a precise estimate of the proportion of procedures performed by EIS. Where a hospital provided a range of use of EIS for a specific transfusion procedure e.g. $31-50 \%$, the lower figure was taken to estimate the number of procedures performed using EIS, and this may have resulted in an under-estimate of the use of EIS. Lastly, the denominator to determine the incidence of WCTs and near miss WCTs was not the number of transfusions administered in each hospital, but the number of blood components provided to each hospital by NHS Blood \& Transplant and the other UK Blood Transfusion Services. Given that a small proportion of blood components provided to hospitals may not be transfused, the use of the number of blood components issued to hospitals may have resulted in a slight under-estimate of the rate of WCTs.

In conclusion, this is the first study to demonstrate a lower incidence of WCTs with EIS compared to manual procedures in a multicenter study using data from a national hemovigilance program. The review of the WCT and near miss WCT events reported to SHOT over 2 years highlights some limitations of both manual and EIS procedures and emphasizes how positive patient identification remains paramount for patient safety. This study also indicates that the implementation of EIS in the UK has been patchy and is rarely used to its full functionality for all three steps. It also shows that the number of hospitals taking up EIS slowed between 2014 and 2017, although more recent informal information from suppliers indicates that uptake has increased since then. Further efforts are needed to hasten the implementation of EIS to improve patient safety in the transfusion process. 


\section{References}

1. Serious Hazards of Transfusion Annual Report, 2017. https://www.shotuk.org/shotreports/report-summary-and-supplement-2017/

2. Fatalities Reported to FDA Following Blood Collection and Transfusion Annual Summary for Fiscal Year 2017. https://www.fda.gov/media/124796/download

3. Serious Hazards of Transfusion Annual Report, 2016. https://www.shotuk.org/wpcontent/uploads/myimages/SHOT-Report-2016_web_11th-July.pdf

4. Linden JV, Wagner K, Voytovich AE, et al. Transfusion errors in New York State: an analysis of 10 years' experience. Transfusion 2000;40:1207-1213.

5. Murphy MF, Fraser E, Miles D, et al. How do we monitor hospital transfusion practice using an end-to-end electronic transfusion management system? Transfusion 2012:52; 2502-2512.

6. Cohen R, Ning S, Yan MTS, Callum J. Transfusion safety: the nature and outcomes of errors in patient registration. Transfusion Medicine Reviews 2019;33:78-83.

7. Saxena S, Ramer L, Shulman IA. A comprehensive assessment program to improve blood-administering practices using the FOCUS-PDA model. Transfusion 2004; 44:1350-6.

8. Turner CL, Casbard AC, Murphy MF. Barcode technology:its role in increasing the safety of transfusion. Transfusion 2003;43:1200-9.

9. Chan JC, Chu RW, Young BW, Chan F, Chow CC, Pang WC,Chan C, Yeung SH, Chow PK, Lau J, Leung PM. Use of an electronic barcode system for patient identification during blood transfusion: 3 year experience in a regional hospital. Hong Kong Med J 2004;10:166-71.

10. Askeland RW, McGrane S, Levitt JS, Dane SK, Greene DL, VandeBerg JA, Walker K, Porcella A, Herwaldt LA, Carmen LT, Kemp JD. Improving transfusion safety: implementation of a comprehensive computerized bar code-based tracking system for detecting and preventing errors. Transfusion 2008;48:1308-17.

11. Kaufman RM, Dinh A, Cohn CS, Fung MK, Gorlin J, Melanson S, Murphy MF, Ziman A, Elahie AL, Chasse D, Degree L, Dunbar NM, Dzik WH, Flanagan P, Gabert K, Ipe TS, Jackson B, Lane D, Raspollini E, Ray C, Sharon Y, Ellis M, Selleng K, Staves J, Yu P, Zeller M, Yazer M; BEST Collaborative. Electronic patient identification for sample labelling reduces wrong blood in tube errors. Transfusion 2018 Dec 14. doi: 10.1111/trf.15102. [Epub ahead of print]. 
12. Murphy MF, Staves J, Davies A, Fraser E, Parker R, Cripps B, Kay J \& Vincent C. How do we approach a major change program using the example of the development, evaluation, and implementation of an electronic transfusion management system. Transfusion 2009; 49:829-837.

13. Serious Hazards of Transfusion Annual Report, 2015. https://www.shotuk.org/wpcontent/uploads/myimages/SHOT-2015-Annual-Report-Web-Edition-Finalbookmarked.pdf

14. Practical Statistics for Medical Research, Douglas G Altman. Chapman \& Hall/CRC Texts in statistical Science, 1990.

15. Serious Hazards of Transfusion Annual Report, 2003. https://www.shotuk.org/wpcontent/uploads/myimages/2010/03/SHOT-Report-2003.pdf

16. Robinson S, Harris A, Atkinson S, Atterbury C, Bolton-Maggs P, et al. The administration of blood components: a British Society for Haematology guideline. Transfusion Medicine 2018; 28:3-21. 
Legends

Appendix: Hospital survey tool about transfusion procedures.

Figure 1. Number and type of each EIS implemented between 1999 and 2017.

Figure 2. Proportion of transfusions for each of the type of EIS in 2016. 
Figure 1: Number and type of each EIS implemented between 1999 and 2017

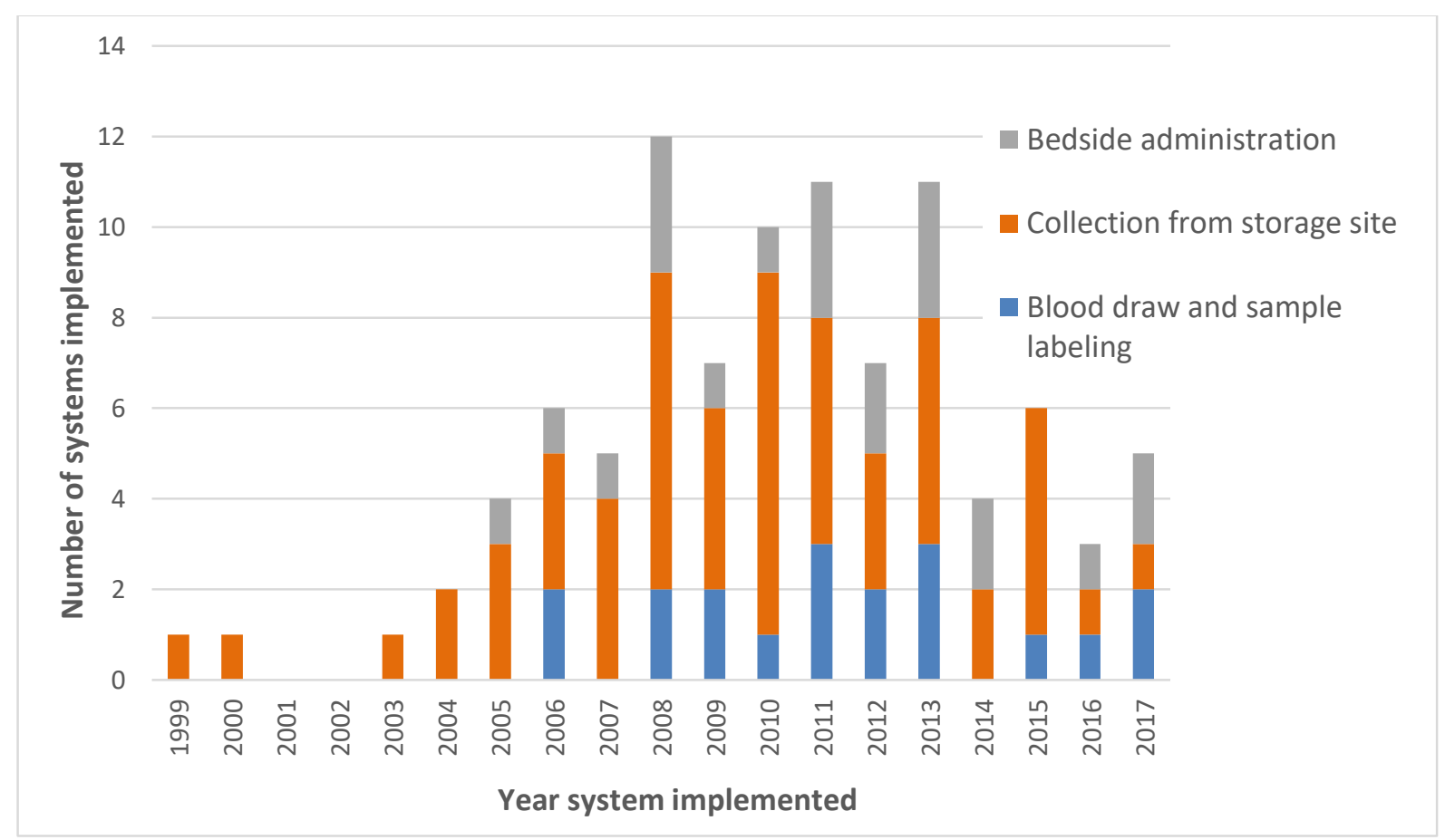


Figure 2: Proportion of transfusions for each of the 3 types of EIS (2016)

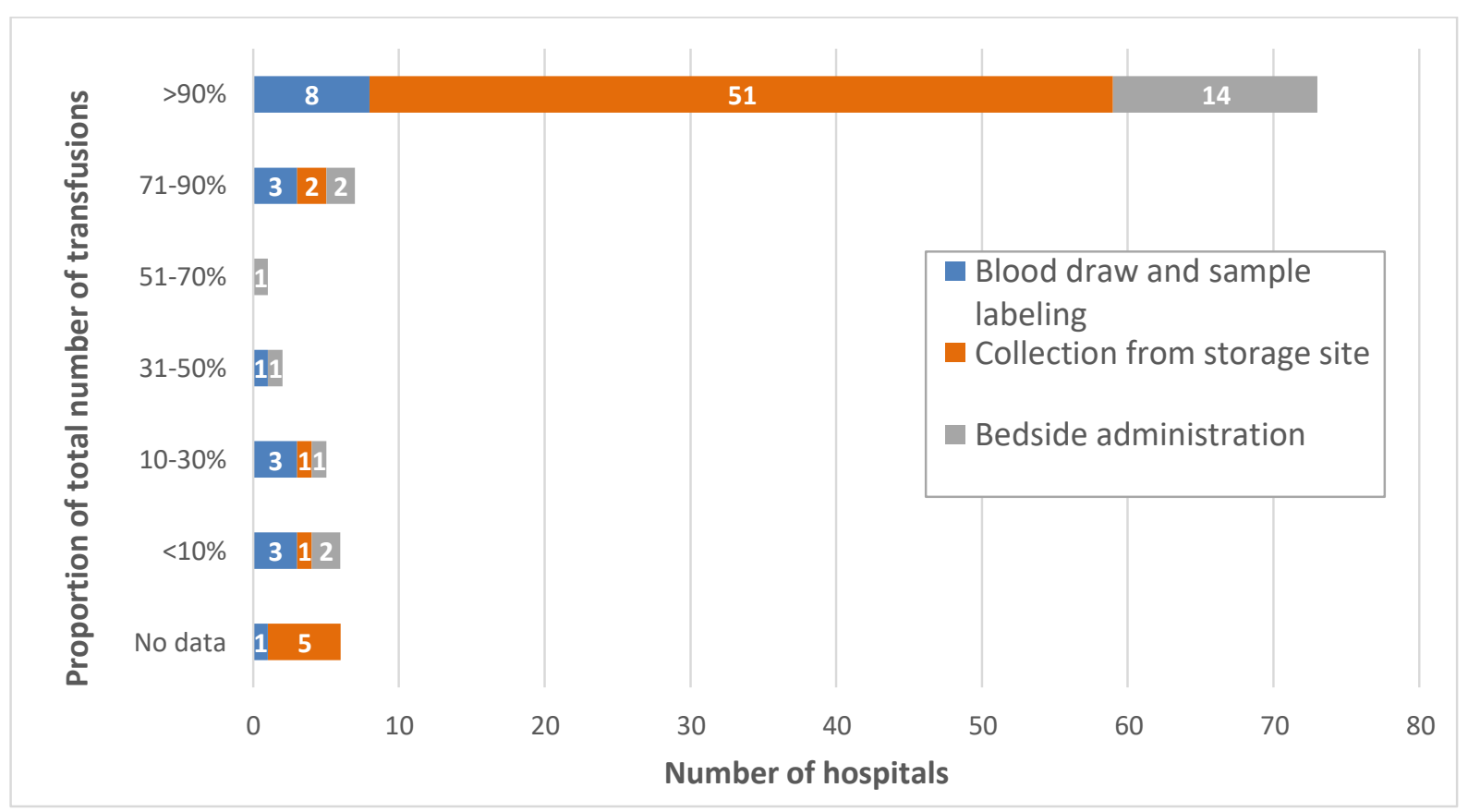


Table 1. Number of hospitals using various combinations of manual and EIS processes and the calculated number of blood components where manual or EIS processes were used

\begin{tabular}{|l|c|l|}
\hline $\begin{array}{l}\text { Combinations of manual and } \\
\text { EIS processes }\end{array}$ & $\begin{array}{l}\text { Number of hospitals (\%) } \\
\text { (Denominator: 93 hospitals that } \\
\text { responded to the survey) }\end{array}$ & $\begin{array}{l}\text { Number of blood components } \\
\text { where manual or EIS } \\
\text { processes were used } \\
\text { (Denominator:1,946,386 units) }\end{array}$ \\
\hline Manual throughout (all 3 steps) & $33(35 \%)$ & $661,380(34 \%)$ \\
\hline $\begin{array}{l}\text { Electronic blood draw, sample } \\
\text { labeling and blood collection }\end{array}$ & $3(3 \%)$ & $23391(1 \%)$ \\
\hline $\begin{array}{l}\text { Electronic blood collection only } \\
\text { Electronic blood collection and } \\
\text { administration only }\end{array}$ & $36(39 \%)$ & $297944(15 \%)$ \\
\hline $\begin{array}{l}\text { Hospitals that had all 3 clinical } \\
\text { electronic blood systems - } \\
\text { sample, collection and } \\
\text { administration }\end{array}$ & $5(5 \%)$ & $57745(3 \%)$ \\
\hline $\begin{array}{l}\text { Number of blood components in } \\
\text { hospitals with EIS but where } \\
\text { EIS was not used }\end{array}$ & $16(17 \%)$ & $552,994(28 \%)$ \\
\hline
\end{tabular}


Table 2. Comparison of WCTs occurring with manual and electronic systems

\begin{tabular}{|c|c|c|c|}
\hline $\begin{array}{l}\text { Step in the } \\
\text { transfusion } \\
\text { process where the } \\
\text { error occurred }\end{array}$ & $\begin{array}{l}\text { WCTs associated with a } \\
\text { manual process/number of } \\
\text { units transfused }\end{array}$ & $\begin{array}{l}\text { WCTs associated } \\
\text { with an electronic } \\
\text { process/number of } \\
\text { units transfused }\end{array}$ & $\begin{array}{l}\text { Crude odds ratio } \\
(95 \% \text { CI }), \text { p-value* }\end{array}$ \\
\hline $\begin{array}{l}\text { Blood draw and } \\
\text { sample labeling }\end{array}$ & $\begin{array}{c}\text { 3/1,570,063 (0.0002\%) } \\
1 \text { in 523,354 units }\end{array}$ & $0 / 376,323$ & $\begin{array}{c}0.60(0.03 \text { to } 11.54) \\
p=1.00\end{array}$ \\
\hline $\begin{array}{l}\text { Collection of } \\
\text { blood from } \\
\text { refrigerator }\end{array}$ & $\begin{array}{c}12 / 1,214,374(0.001 \%) \\
1 \text { in } 101,195 \text { units }\end{array}$ & $\begin{array}{c}3 / 732,012(0.0004 \%) \\
1 \text { in } 244,004 \text { units }\end{array}$ & $\begin{array}{c}0.41(0.11 \text { to } 1.47) \\
p=0.191\end{array}$ \\
\hline $\begin{array}{l}\text { Blood } \\
\text { administration }\end{array}$ & $\begin{array}{c}2 / 1,535,709(0.0001 \%) \\
1 \text { in } 267,854 \text { units }\end{array}$ & $0 / 410,677$ & $\begin{array}{c}0.75(0.04 \text { to } 15.58) \\
\mathrm{p}=1.00\end{array}$ \\
\hline
\end{tabular}

*p-values are calculated from 2-sided Fisher's exact test. 
Table 3. Comparison of near miss WCTs occurring with manual and electronic systems

\begin{tabular}{|l|c|c|c|}
\hline & $\begin{array}{c}\text { Near miss WCTs } \\
\text { associated with a } \\
\text { manual process/number } \\
\text { of units transfused }\end{array}$ & $\begin{array}{c}\text { Near miss WCTs } \\
\text { associated with an } \\
\text { electronic } \\
\text { process/number of } \\
\text { units transfused }\end{array}$ & $\begin{array}{c}\text { Crude odds ratio (95\% } \\
\text { CI), p-value }\end{array}$ \\
\hline $\begin{array}{l}\text { Blood draw and } \\
\text { sample labeling }\end{array}$ & $\begin{array}{c}452 / 1,570,063(0.079 \%) \\
\text { in } 3,474 \text { units }\end{array}$ & $\begin{array}{c}17 / 376,323 \\
(0.004 \%)\end{array}$ & $\begin{array}{c}0.16(0.10 \text { to } 0.25), \\
\mathrm{p}<0.001^{* *}\end{array}$ \\
\hline $\begin{array}{l}\text { Collection of } \\
\text { blood from } \\
\text { refrigerator }\end{array}$ & $30 / 1,214,374(0.002 \%)$ & $0 / 732,012$ & $0.03(0.00$ to 0.44$)$, \\
$\mathrm{p}<0.001 *$
\end{tabular}

*p-values are calculated from 2-sided Fisher's exact test.

**p-values are calculated from Chi-square test 
Supplementary Table 1. Step in the transfusion process where the primary error occurred

\section{leading to a WCT}

\begin{tabular}{|c|c|c|c|c|}
\hline \multirow{2}{*}{$\begin{array}{l}\text { Step in the } \\
\text { transfusion process } \\
\text { primary error } \\
\text { occurred }\end{array}$} & \multirow{2}{*}{$\begin{array}{l}\text { Number of } \\
\text { WCTs } \\
\text { Total = } 57\end{array}$} & \multicolumn{3}{|c|}{ Process used at each step } \\
\hline & & $\begin{array}{l}\text { Electronic } \\
\text { Total }=\mathbf{3}\end{array}$ & $\begin{array}{l}\text { Manual } \\
\text { Total = } 17\end{array}$ & $\begin{array}{l}\text { N/A } \\
\text { Total }=\mathbf{3 7}\end{array}$ \\
\hline Request & 4 & N/A & N/A & 4 \\
\hline $\begin{array}{l}\text { Blood draw and sample } \\
\text { labeling }\end{array}$ & 3 & $\mathbf{0}$ & 3 & N/A \\
\hline Sample receipt & 5 & N/A & N/A & 5 \\
\hline Testing & 17 & N/A & N/A & 17 \\
\hline Component selection & 8 & N/A & N/A & 8 \\
\hline Component labelling & 1 & N/A & N/A & 1 \\
\hline Collection & 15 & 3 & 12 & N/A \\
\hline Prescription & $\mathbf{0}$ & N/A & N/A & $\mathbf{0}$ \\
\hline Administration & 2 & $\mathbf{0}$ & 2 & N/A \\
\hline Miscellaneous & 2 & N/A & N/A & 2 \\
\hline
\end{tabular}

N/A - not applicable 
Supplementary Table 2. Number of near miss WCTs using a manual process or EIS and the step in the transfusion process where the primary error occurred

\begin{tabular}{|l|c|c|c|}
\hline $\begin{array}{l}\text { Step in transfusion where the } \\
\text { primary error occurred }\end{array}$ & $\begin{array}{l}\text { No. of errors } \\
\text { Total = 571 }\end{array}$ & $\begin{array}{l}\text { Electronic } \\
\text { Total = 37 }\end{array}$ & $\begin{array}{l}\text { Manual } \\
\text { Total = 497 }\end{array}$ \\
\cline { 4 - 4 } $\begin{array}{l}\text { Blood draw and sample } \\
\text { labeling }\end{array}$ & $\mathbf{4 6 9}$ & $\mathbf{1 7}$ & $\mathbf{4 5 2}$ \\
\hline Blood bank & & & N/A \\
\hline Collection & $\mathbf{2 0}$ & $\mathbf{0}$ & $\mathbf{3 0}$ \\
\hline Administration & $\mathbf{3 0}$ & $\mathbf{2 0}$ & $\mathbf{2}$ \\
\hline Other clinical steps & $\mathbf{2 2}$ & $\mathbf{0}$ & $\mathbf{1 3}$ \\
\hline NA/unknown & $\mathbf{1 3}$ & N/A & N/A \\
\hline
\end{tabular}

N/A - not applicable, total $=37$ 
Supplementary Table 3. Step in the transfusion process where the primary error for near miss WCTs was detected

\begin{tabular}{|c|c|c|c|c|c|c|c|}
\hline & $\begin{array}{l}\text { No of } \\
\text { primary }\end{array}$ & Manual & $\begin{array}{l}\text { Where wa } \\
\text { detected }\end{array}$ & the error & Electronic & $\begin{array}{l}\text { Where wa } \\
\text { detected }\end{array}$ & the error \\
\hline \multirow[t]{6}{*}{$\begin{array}{l}\text { Blood draw } \\
\text { and sample } \\
\text { labeling }\end{array}$} & \multirow[t]{6}{*}{469} & \multirow[t]{6}{*}{452} & Sample & $\begin{array}{l}6 \\
3 \text { manual } \\
3 \text { un- } \\
\text { known }\end{array}$ & \multirow[t]{6}{*}{17} & Sample & 0 \\
\hline & & & Lab & 427 & & Lab & 17 \\
\hline & & & Collection & 1 & & Collection & 0 \\
\hline & & & Admin & 1 & & Admin & 0 \\
\hline & & & Other & 3 & & Other & 0 \\
\hline & & & Unknown & 14 & & $\begin{array}{l}\text { Un- } \\
\text { known }\end{array}$ & 0 \\
\hline \multirow[t]{6}{*}{ Collection } & \multirow[t]{6}{*}{30} & \multirow[t]{6}{*}{30} & Sample & 0 & \multirow[t]{6}{*}{0} & Sample & 0 \\
\hline & & & Lab & 0 & & Lab & 0 \\
\hline & & & Collection & 6 & & Collection & 0 \\
\hline & & & Admin & 21 & & Admin & 0 \\
\hline & & & Other & 0 & & Other & 0 \\
\hline & & & Unknown & 3 & & Unknown & 0 \\
\hline \multirow[t]{6}{*}{ Administration } & \multirow[t]{6}{*}{$22 *$} & & Sample & 0 & \multirow[t]{6}{*}{20} & Sample & 0 \\
\hline & & & Lab & 0 & & Lab & 0 \\
\hline & & & Collection & 0 & & Collection & 0 \\
\hline & & & Admin & 2 & & Admin & 20 \\
\hline & & & Other & 0 & & Other & 0 \\
\hline & & & Unknown & 0 & & Unknown & 0 \\
\hline
\end{tabular}

*22 errors made immediately prior to administration checking procedure

Admin $=$ administration 